- More PBRNs are developing linkages to the community in the hybrid PBRN/CBPR model and achieving success in improving population health.

NAPCRG will continue the new tradition of hosting the PBRN conference from 2014 to 2016 after receiving a multi-year conference grant from AHRQ. We have broadened the representation of the planning committee to include perspectives from patients, community clinicians, federal agencies, PBRN coordinators/staff, new PBRNs, and Canadian PBRNs. The 2014 conference will be held June 30 to July 1, 2014, at the Bethesda, Maryland Hyatt hotel and promises to be filled with sessions and presentations on the latest, priority topics and findings from PBRN research.

This project was supported by grant number R13HS022217 from the Agency for Healthcare Research and Quality. The content is solely the responsibility of the authors and does not necessarily represent the official views of the Agency for Healthcare Research and Quality.

Rowena J. Dolor, MD, MHS, Duke University Medical Center,

Duke Primary Care Research Consortium

Lyle J. Fagnan, MD, Oregon Health and Science University,

Oregon Rural Practice-Based Research Network

\section{AHRQ UPDATES ON PRIMARY CARE RESEARCH: RAISING AWARENESS ABOUT CARING FOR PATIENTS WITH MULTIPLE CHRONIC CONDITIONS}

In order to raise awareness about improving care for people with multiple chronic conditions (MCC), the Agency for Healthcare Research and Quality (AHRQ) has developed an animated video and an infographic. These creative, plain language materials were designed to help interested audiences learn about the importance of this topic and understand some of the key issues related to multiple chronic conditions.

The animated video depicts "A Day in the Life" of Mae, a 52-year-old woman living with multiple chronic conditions. We see her as she begins her morning with her family and then proceeds throughout the day, attending multiple appointments with different health care providers. The video, supported by voice-over narration, depicts the difficulty and effort necessary for Mae to keep up with the numerous and sometimes conflicting instructions, treatments, and prescriptions she receives from her various providers, while also balancing the demands of her busy life. Toward the end, the story shifts, showing another and much better option for Mae. In this option, she, her family, and her clinicians work together to create a care plan just for her. The plan coordinates the care for her multiple conditions and takes into account other factors in her life that affect her health. It ends with the following call to action, "Working together we can transform the health care system to serve the whole person with all their complexities. It will take everyone-clinicians, researchers, policymakers, patients and families - working together to get it done."

An infographic uses graphic visual representations to present data and other complex information in a way that is visually compelling and can be understood quickly and easily. AHRQ's MCC infographic (see below) contains a series of graphics to describe common chronic conditions; the large and growing prevalence of $\mathrm{MCC}_{i}$ the enormous cost of MCC for individuals, Medicare, and the US health care system in general $_{i}$ and the impact of MCC on patients and families. The infographic provides an innovative way to convey key information about the impact and importance of MCC. 
To preview AHRQ's MCC video and the MCC infographic, please visit: http://www.ahrq.gov/ professionals/prevention-chronic-care/decision/mcc/.
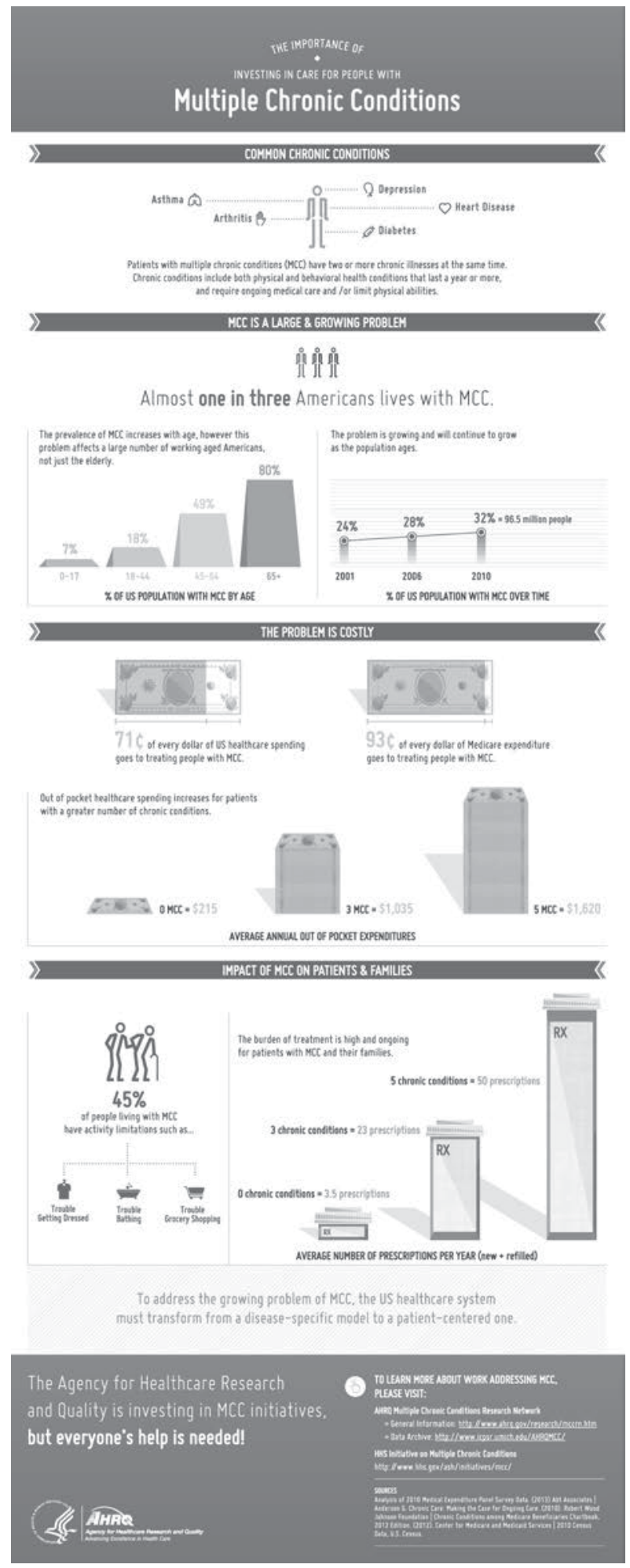

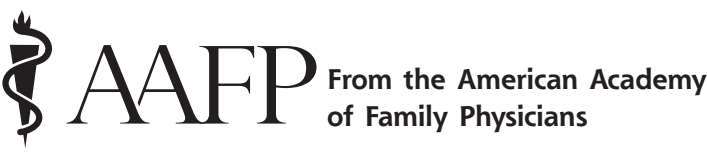

Ann Fam Med 2014;178-179. doi: 10.1370/afm.1637.

\section{AMERICANS WANT PHYSICIANS HANDLING THEIR HEALTH CARE}

Family physicians recently received one of the best possible gifts from the American public - a huge "thumbs up" and vote of confidence as to whom they want overseeing their health care.

That's the headline news pulled from survey results recently released that indicate

- $72 \%$ of American adults prefer physicians to nonphysicians when it comes to health care

- $90 \%$ of adults would choose a physician to lead their "ideal medical team" when given the choice

- By a greater than two-to-one margin, adults see physicians and family physicians as more knowledgeable, experienced, trusted and up-to-date on medical advances than nonphysicians

AAFP President Reid Blackwelder, MD, of Kingsport, Tennessee, called the news "outstanding."

"It's exciting, because anytime you get a survey that overwhelmingly says patients appreciate you and want to see you, that's good news," said Blackwelder. "I see this as personal affirmation. Our patients value us. They trust us."

Blackwelder said the survey results accomplished something legislators and policymakers have been unable to do despite their constant talk about the value of primary care. "This survey puts a face-a family physician face-on the message that's being repeated nationwide that team-based care and primary care are critical to the successful transformation of health care delivery in this country," said Blackwelder.

"Even in these challenging times, we universally are seen as knowledgeable and trustworthy; our patients want to see us when they have health care needs, and overwhelmingly, they want us to be the leader of their health care team," he added.

In a related press release, Blackwelder detailed exactly what patients value in their physicians. "They understand that physicians have the medical expertise necessary to know whether an apparently simple symptom signals a complication of a chronic condition, the onset of a new condition affecting multiple organs, or a short-term and easily treated problem," said Blackwelder. "They want that expertise for themselves and their loved ones."

The AAFP-commissioned survey was conducted online November 8-15, 2013 by Ipsos, a global market 